\title{
Energy balance, metabolism, hydration, and performance during strenuous hill walking: the effect of age
}

Citation for published version (APA):

Ainslie, P. N., Campbell, I. T., Frayn, K. N., Humphreys, S. M., MacLaren, D. P., Reilly, T., \& Westerterp, K. R. (2002). Energy balance, metabolism, hydration, and performance during strenuous hill walking: the effect of age. Journal of Applied Physiology, 93(2), 714-723.

https://doi.org/10.1152/japplphysiol.01249.2001

Document status and date:

Published: 01/01/2002

DOI:

10.1152/japplphysiol.01249.2001

Document Version:

Publisher's PDF, also known as Version of record

\section{Document license:}

Taverne

Please check the document version of this publication:

- A submitted manuscript is the version of the article upon submission and before peer-review. There can be important differences between the submitted version and the official published version of record.

People interested in the research are advised to contact the author for the final version of the publication, or visit the DOI to the publisher's website.

- The final author version and the galley proof are versions of the publication after peer review.

- The final published version features the final layout of the paper including the volume, issue and page numbers.

Link to publication

\footnotetext{
General rights rights.

- You may freely distribute the URL identifying the publication in the public portal. please follow below link for the End User Agreement:

www.umlib.nl/taverne-license

Take down policy

If you believe that this document breaches copyright please contact us at:

repository@maastrichtuniversity.nl

providing details and we will investigate your claim.
}

Copyright and moral rights for the publications made accessible in the public portal are retained by the authors and/or other copyright owners and it is a condition of accessing publications that users recognise and abide by the legal requirements associated with these

- Users may download and print one copy of any publication from the public portal for the purpose of private study or research.

- You may not further distribute the material or use it for any profit-making activity or commercial gain

If the publication is distributed under the terms of Article $25 \mathrm{fa}$ of the Dutch Copyright Act, indicated by the "Taverne" license above, 


\title{
Energy balance, metabolism, hydration, and performance during strenuous hill walking: the effect of age
}

\author{
P. N. AINSLIE, ${ }^{1}$ I. T. CAMPBELL,${ }^{2}$ K. N. FRAYN,${ }^{3}$ S. M. HUMPHREYS, ${ }^{3}$ \\ D. P. M. MACLAREN,${ }^{1}$ T. REILLY, ${ }^{1}$ AND K. R. WESTERTERP ${ }^{4}$ \\ ${ }^{1}$ Research Institute for Sport and Exercise Sciences, Liverpool John Moores University, \\ Liverpool L3 2ET; ${ }^{2}$ University Department of Anaesthesia, Withington Hospital, \\ Manchester M20 2LR; ${ }^{3}$ Oxford Lipid Metabolism Group, Radcliffe Infirmary, Oxford OX2 6HE, \\ United Kingdom; and ${ }^{4}$ Department of Human Biology, Maastricht University, The Netherlands
}

Received 21 December 2001; accepted in final form 26 April 2002

\begin{abstract}
Ainslie, P. N., I. T. Campbell, K. N. Frayn, S. M. Humphreys, D. P. M. MacLaren, T. Reilly, and K. R. Westerterp. Energy balance, metabolism, hydration, and performance during strenuous hill walking: the effect of age. J Appl Physiol 93: 714-723, 2002; 10.1152/japplphysiol. 01249.2001.-We aimed to examine the effect of age on energy balance, metabolism, hydration, and performance during 10 days of strenuous hill walking. Seventeen male subjects were divided into two groups according to their age. The nine subjects in group 1 constituted the younger group (age $24 \pm 3 \mathrm{yr}$ ), whereas eight older subjects were in group 2 (age $56 \pm 3$ yr). Both groups completed 10 consecutive days of high-intensity hill walking. Mean (range) daily walking distances and ascent were $21 \mathrm{~km}(10-35 \mathrm{~km})$ and $1,160 \mathrm{~m}$ $(800-2,540 \mathrm{~m})$, respectively. Energy intake was calculated from weighed food intake, and energy expenditure was measured by the doubly labeled water method. Blood and urine were sampled on alternative days to determine any changes in metabolism and hydration during the 10 days. Subjects also completed a battery of tests that included muscular strength (handgrip), jump performance, cognitive processing time, and flexibility. The younger group remained hydrated, whereas the older group became progressively dehydrated, indicated by a near twofold increase in urine osmolality concentration on day 11. This increased urine osmolality in the older group was highly correlated with impairment in vertical-jump performance $(r=-0.86 ; P<0.05)$ and decreased cognitive processing time $(r=0.79 ; P<0.05)$. Despite energy expenditure of $\sim 21 \mathrm{MJ} /$ day, body mass was well maintained in both groups. Both groups displayed a marked increase in fat mobilization, reflected in significantly lowered prewalk insulin concentrations and elevated postwalk glycerol and nonesterified fatty acid concentrations. Despite the dehydration and impaired performance in the older group, blood glucose concentrations were well maintained in both groups, probably mediated via the increased mobilization of fat.

field study; metabolism; age and hill walking
\end{abstract}

THE PROLONGED DURATION of a typical hill walk places exceptional demands on the participants. The specific demands of hill walking tend to involve activity of

Address for reprint requests and other correspondence: P. N. Ainslie, Research Institute for Sport and Exercise Sciences, Liverpool John Moores Univ., Liverpool L3 5UX, UK (E-mail: humpains@livjm.ac.uk). varying intensity and duration, both of which are influenced by factors such as physical fitness, dietary intake, backpack weight, and environmental conditions (3). Despite the popularity of hill walking and the increasingly acknowledged problem of accidents in mountainous environments, the ability of safety organizations to design educational material concerning this hazard is hindered by a lack of knowledge of the physiological and psychomotor responses to such events, which are often pursued over consecutive days. The information that is available derives from the pioneering work of Pugh (37-40), supplemented by descriptions of exposure incidents $(28,28 \mathrm{a}, 28 \mathrm{~b}, 31,38$, $35,44)$.

Our recent research into the energy cost of a $12-\mathrm{km}$ hill walk demonstrated a high energy expenditure (EE) of $14.5 \mathrm{MJ}$ for the walk [recorded via continuous measurement of respiratory gas exchange by means of indirect calorimetry (3)]. In this study, food and fluid were allowed ad libitum; nevertheless, subjects became dehydrated and lost, on average, $2 \mathrm{~kg}$ in body mass. Despite the high energetic cost of the walk, dehydration, and serious physiological stress, subjects demonstrated little change in psychomotor control during and after the walk. Furthermore, despite the difference between energy intake and expenditure, blood glucose and triacylglycerol (TAG) concentrations were maintained. The major source of energy was enhanced fat oxidation, probably from adipose tissue lipolysis (3).

Thermoregulatory and cardiovascular functions as well as cognitive function are adversely influenced by body water deficits $(1,22,32,41)$. For many complex tasks, both mental decision making and physiological functioning are closely related (41). As a result, dehydration probably has more profound effects on real-life tasks than on solely physiological responses. Healthy older subjects may be more prone to dehydration than their younger counterparts $(29,42)$ because of a blunted thirst sensation leading to a reduced fluid intake $(29,42)$. In hill walking, dehydration may de-

The costs of publication of this article were defrayed in part by the payment of page charges. The article must therefore be hereby marked "advertisement" in accordance with 18 U.S.C. Section 1734 solely to indicate this fact. 
crease thermoregulatory and cognitive functioning, which could impair decision making, leading to an increased susceptibility to fatigue and injury in a mountainous environment.

We aimed to extend our previous investigations into a hill-walking event to cover 10 consecutive days of walking. Furthermore, there have been no studies that have considered the effect of age on the potential stress of such activities. We aimed, therefore, to quantify some relevant responses that are important in the safety of hill walkers, such as the likelihood of dehydration, impaired performance, and the ability to maintain glycemia, and the possible effect that age may have on these responses. This type of study may be important in adding to the mostly anecdotal information regarding exposure and recreational activities.

Based on our initial study (3), we first predicted that, due to the large energy cost of such events, subjects would have difficulties in maintaining body mass during sustained activity over several days. Second, due to the envisaged physiological stress, significant alterations in metabolism, hydration, and performance may become apparent throughout the 10 consecutive days of hill walking. Finally, we postulated that older subjects may experience a higher strain and impairment than the young, possibly as a consequence of lower physical fitness and a blunted thirst response that may impair their ability to rehydrate effectively.

\section{METHODS}

Subjects. Seventeen male subjects were divided into two groups according to their age: group 1 [younger; age (mean \pm SD) $24 \pm 3$ yr; range $20-28$ yr; $n=9$ ] and group 2 (older; $56 \pm$ $4 \mathrm{yr}$; range $51-60 \mathrm{yr} ; n=8$ ). The study was reviewed and approved by the Human Ethics Committee of Liverpool John Moores University. Subjects gave written consent to participate in the study after they had been fully informed of the nature, purpose, and possible risks associated with the study. Physical characteristics of the subjects are shown in Table 1. The majority of the subjects were active and experienced hill walkers.

Protocol. Both groups completed 10 consecutive days of high-intensity hill walking during the month of April in the Scottish highlands. Mean (range) daily walking distances and ascent were $21 \mathrm{~km}(10-35 \mathrm{~km})$ and $1,160 \mathrm{~m}(800-2,540$ m) above sea level, respectively, consisting of a range of gradients and terrain typical of a mountainous hill walk. The

Table 1. Physical characteristics of the subjects

\begin{tabular}{llc}
\hline \hline & \multicolumn{1}{c}{ Older } & Younger \\
\hline Age, $\mathrm{yr}$ & $56.4 \pm 3.7$ & $24.4 \pm 2.9$ \\
Height, m & $1.78 \pm 0.04$ & $1.78 \pm 0.1$ \\
Body mass, kg & $76.3 \pm 11.8$ & $75.8 \pm 7.4$ \\
BMI, $\mathrm{kg} / \mathrm{m}^{2}$ & $24.6 \pm 2.3$ & $22.9 \pm 2.1$ \\
TBW, liter & $42.0 \pm 4.9$ & $43.3 \pm 4.7$ \\
Fat-free mass, $\mathrm{kg}$ & $57.6 \pm 6.7$ & $59.3 \pm 6.5$ \\
Fat mass, $\mathrm{kg}$ & $17.9 \pm 7.4$ & $12.8 \pm 2.9$ \\
VOO$_{2}$ peak, $\mathrm{ml} \cdot \mathrm{kg}^{-1} \cdot \mathrm{min}^{-1}$ & $46.7 \pm 7.3$ & $56.4 \pm 6.9$ \\
\hline
\end{tabular}

Mean values \pm SD of 8 subjects in the older group and 9 subjects in the younger group. Refer to METHODS for calculations and assumptions. BMI, body mass index; TBW, total body water; $\dot{\mathrm{V}}_{2}$ peak, peak oxygen consumption. total ascent and distance covered in the 10-day study were $\sim 12$ and $180 \mathrm{~km}$, respectively. Experimental design is outlined in Fig. 1. Living accommodations were provided for the subjects and were located close to the hill walks. Subjects awoke each morning between 0530 and 0630 and completed the preliminary experiments before the hill walk (Fig. 1). Self-paced walking began each day between 0830 and 0930 . Subjects selected their own food and fluids for the walk that were preweighed before starting.

Food and water intakes. Weighed food and water intakes were measured with a 10-day dietary record. Subjects received instructions on how to keep a food record. Food and water were allowed ad libitum. Data on the food records were used to calculate intakes of total energy, protein, fat, carbohydrate $(\mathrm{CHO})$, and alcohol with a computer program based on food tables (CompEat, version 5, Grantham, UK). Total water intake was calculated from reported food and water intakes and the calculated amount of metabolic water. The amount of metabolic water was estimated from protein, fat, and $\mathrm{CHO}$ intake derived from the 10-day food record. Oxidation of protein, fat, and $\mathrm{CHO}$ gives $0.41,1.07$, and $0.6 \mathrm{ml}$ water/g, respectively (18).

$E E$, water loss, and physical activity level. EE using the doubly labeled water technique ( $\left.\mathrm{EE}_{\mathrm{DLW}}\right)$ was measured according to Westerterp (47). The estimated coefficient of variance (CV) for $\mathrm{EE}_{\mathrm{DLW}}$ was $7 \%$ (47), whereas water loss calculated by using the deuterium method has an estimated CV of $7 \%$ (47). In the evening of day 0 , subjects were given a weighted dose of a mixture of 99.84 atom $\%{ }^{2} \mathrm{H}_{2} \mathrm{O}$ in 10.05 atom $\% \mathrm{H}_{2}^{18} \mathrm{O}$, such that ${ }^{2} \mathrm{H}$ and ${ }^{18} \mathrm{O}$ increased from baseline by $\geq 150$ and $\geq 300 \mathrm{ppm}$, respectively. A background urine sample was collected in the evening of day 0 . Additional urine samples were collected on day 1 (from the second void of the day and during the evening), in the morning and evening of days 5 and 10 , and in the morning of day 11 . Isotope abundances in the urine samples were measured with an isotope-ratio mass spectrometer (Optima, VG Isogas). The calculation of $\mathrm{EE}$ from the rate of $\mathrm{CO}_{2}$ production $\left(\mathrm{rCO}_{2}\right)$ is based on the relationship

$$
\mathrm{rCO}_{2}=\frac{k_{\mathrm{O}} \times D_{\mathrm{O}}-k_{\mathrm{H}} \times D_{\mathrm{H}}}{2 \times f_{3}}-\frac{f_{2}-f_{1}}{2 \times f_{3}} \times \mathrm{rGf}
$$

where $k_{\mathrm{O}}, D_{\mathrm{O}}, k_{\mathrm{H}}$, and $D_{\mathrm{H}}$ are elimination rates and dilution spaces from ${ }^{18} \mathrm{O}$ and ${ }^{2} \mathrm{H}$, respectively. Factors $f_{1}, f_{2}$, and $f_{3}$ are for fractionation of ${ }^{2} \mathrm{H}$ in water vapor $(0.941),{ }^{18} \mathrm{O}$ in water vapor (0.992), and ${ }^{18} \mathrm{O}$ in $\mathrm{CO}_{2}$ (1.039), respectively, and $\mathrm{rGf}$ is the rate of isotopically-fractionated gaseous water loss. Then

$$
\mathrm{rGf}=1.3 \times 1.77 \times \mathrm{rCO}_{2}
$$

assuming that breath is saturated with water and contains $3.5 \% \mathrm{CO}_{2}$ fractionated breath water $\left(=1.77 \times \mathrm{rCO}_{2}\right)$ and that transcutaneous fractionated (nonsweat) water loss amounts to $\sim 30 \%$ of breath water. Then

$$
\mathrm{rCO}_{2}=0.455 \mathrm{~N} \times\left(1.01 \times k_{\mathrm{O}}-1.04 \times k_{\mathrm{H}}\right)
$$

where $N$ is the total body water (TBW) calculated from the isotope dilution spaces $\left[\left(D_{\mathrm{O}} / 1.01+D_{\mathrm{H}} / 1.04\right) / 2\right]$ at the start of the observation period, corrected for the change over the observation period. The latter correction is calculated from the initial and final body mass of the subjects during the study, assuming the change in the body water volume is linear and proportional to the change in body mass. $\mathrm{CO}_{2}$ production was converted to EE by using an energy equivalent based on the individual macronutrient composition of the diet. The $\mathrm{EE}_{\mathrm{DLW}}$ was calculated over the same 
Fig. 1. Summary of experimental design. Shorter bars indicate AM collection only, whereas longer bars indicate both AM and PM collections were taken. EE, energy expenditure; EI, energy intake, weighted food and fluid intake; $\mathrm{BMR}_{\mathrm{WHO}}$, basal metabolic rate estimated by using a formula for age, height, and weight (19); PA, physical activity assessed with triaxial accelerometers; BM, nude body mass recorded, after voiding, first thing every morning; Anthropometry, limb circumference and skinfold measurements; Performance, tests of grip strength, flexibility, vertical jump (muscular power), and reaction time (cognitive function); Hydration, urine collection for the assessment of urine osmolality and perception of thirst; Blood sample, 9-ml venous blood sample.

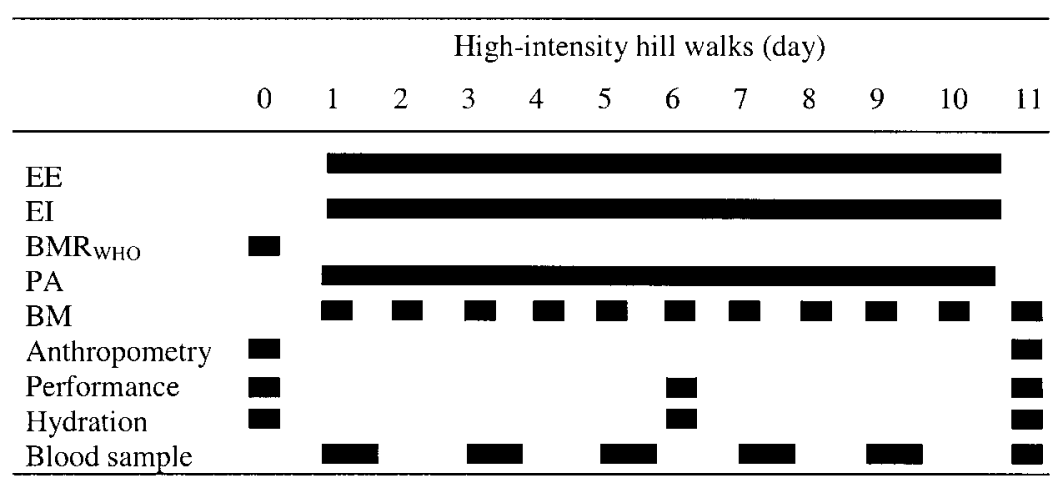

10-day period, during which subjects recorded their food intakes.

The percent under reporting of food intake was calculated by using the $\mathrm{EE}_{\mathrm{DLW}}$ as follows

Under reporting $=$

$$
\left[\left(\text { Energy intake }-\mathrm{EE}_{\mathrm{DLW}}\right) / \mathrm{EE}_{\mathrm{DLW}}\right] \times 100 \%
$$

The percent under eating was calculated from the change in body mass over the 10 days, assuming $1 \mathrm{~kg}$ of body mass to be $30 \mathrm{MJ}$ [75\% fat mass, $25 \%$ fat-free mass (FFM), with $73 \%$ water] $(23,51)$

Under eating $=$

$\left[(\Delta\right.$ body mass $\times 30 \mathrm{MJ} / 10$ days $\left.) / \mathrm{EE}_{\mathrm{DLW}}\right] \times 100 \%$

Physical activity level (PAL) was calculated by the ratio of the averaged daily $\mathrm{EE}_{\mathrm{DLW}}$ to the estimated basal metabolic rate (BMR) $(23,47)$.

BMR measurements. BMRs were estimated (in kilojoules per day) by using an equation including age, sex, body mass (in kilograms), and height (in meters) (19)

$$
\mathrm{BMR}=64.4 \times \text { body mass }+113 \times \text { height }+3,000
$$

In a recent study, no differences were reported between the estimation of BMR with the use of this formula and with direct measurement (23).

Daily physical activity. Physical activity over the 10-day interval was registered by using a triaxial accelerometer (Tracmor, Philips Research, Eindhoven, the Netherlands), consisting of three uniaxial piezoelectric accelerometers attached to the lower back of the subjects with an elastic belt $(33,49)$. The accelerometer calculates the sum of the rectified and integrated acceleration curves from the anteroposterior, mediolateral, and longitudinal axis of the trunk $(33,49)$. The time period for integration was set at $1 \mathrm{~min}$. Subjects were instructed to wear the accelerometer during waking hours, except during bathing and showering.

Body composition. Energy balance was checked by measuring changes in body mass each day. Subjects were instructed to record their nude body mass each morning before consuming any food or beverages and after voiding with calibrated balance scales accurate to $0.1 \mathrm{~kg}$. On day 0, TBW was measured by isotope dilution $\left(\mathrm{H}_{2}^{18} \mathrm{O}\right)$. FFM was calculated as FFM = TBW/0.73, and fat mass was calculated as the difference between body mass and FFM. FFM was assumed to be $27 \%$ protein and $73 \%$ water; fat mass was assumed to be $100 \%$ fat. To estimate changes before and immediately after the experiment, FFM was also estimated by using the equation (55)

$$
\begin{aligned}
\mathrm{FFM}=(40.99+1.0435 \times & \text { body mass }) \\
& -(0.6734 \times \text { abdomen girth })
\end{aligned}
$$

Fat mass was calculated as body mass minus FFM. Percent body fat was estimated from skinfold thicknesses measured with Harpenden skinfold callipers (John Bull, British Indicators, Leicester, UK) over the biceps, triceps, and subscapular and suprailiac areas (15). Three repeated measurements were performed by the same trained investigator for each site, and the mean value was calculated. Limb circumferences (calf, quadriceps, waist, abdomen, and bicep) were estimated from three sequential measurements that were made before and after the experiment on each subject by the same trained investigator using a spring-loaded fiberglass anthropometric tape.

Physical fitness. Fitness level was established by using a continuous incremental treadmill test to voluntary exhaustion (4). After a 5-min warm-up, all subjects started running at $10 \mathrm{~km} / \mathrm{h}$, and this speed increased by $2 \mathrm{~km} / \mathrm{h}$ every $2 \mathrm{~min}$. After $2 \mathrm{~min}$ at $16 \mathrm{~km} / \mathrm{h}$, the speed did not increase further, while an incline increase of $2 \%$ was added every 2 min. Subjects were verbally encouraged throughout the test and continued until they reached volitional exhaustion. A plateau in the oxygen consumption ( $\dot{\mathrm{V}}_{2}$ )-to-work relationship was reached in only two subjects; therefore, the highest aerobic power was expressed as peak $\dot{\mathrm{V}}_{2}\left(\dot{\mathrm{V}}_{2}\right.$ peak $)$ and not maximal $\dot{\mathrm{V}}_{2}$. Verification of $\dot{\mathrm{V}}_{2}$ peak was confirmed by using established physiological criteria as outlined by the American College of Sports Medicine (4). These criteria for maximal aerobic performance include forced mean expiratory volume, leveling off of $\dot{\mathrm{V}}_{2}$, respiratory exchange ratio $>1.15$, and ratings of perceived exertion of 20 or heart rate at agepredicted maximal values (4). Subjects were required to reach at least two of the established physiological criteria for verification of $\dot{\mathrm{V}}_{2}$ peak. The same criteria and procedures were used for all subjects.

Hydration and performance. In the morning before walking on days 1,6, and 11, subjects provided a urine sample for the analysis of urine osmolality to assess hydration status. Urine osmolality was determined in triplicate by the use of the freezing point-depression method (model 3300, Advanced Micro-osmometer, Vitech Scientific, West Sussex, UK). Perception of thirst was assessed with a $100-\mathrm{mm}$ visual analog rating scale labeled from "not at all" to "extremely." The nature of this rating scale and its use and validity in relation to food consumption have been described previously $(12,25)$. Furthermore, care was taken to ensure that both age groups interpreted the scales in a similar manner. 
Likewise, in the morning before walking on days 1,6, and 11 , subjects completed a battery of psychomotor performance tests that included choice reaction time (cognitive processing time), grip strength (motor function), flexibility, and vertical jump (muscular power) tests. An eight-choice reaction-time test for a finger response was assessed on a laptop computer. Motor function was assessed by means of a handgrip dynamometer (Taki, Narragansett, Japan). Flexibility was measured by using a conventional "sit-n-reach" test (4). Finally, vertical jump (muscular power) performance was assessed in the ability to perform a maximal jump from an electronic force platform. Subjects were fully familiarized with the use of the equipment, and each test was performed three times in a balanced fashion.

Analytical methods. Blood samples were obtained from subjects in a semireclined position before and immediately on completion of the walk (Fig. 1). Venous blood samples $(9 \mathrm{ml})$ were drawn from a superficial forearm vein with minimum stasis. From the blood samples, plasma was separated rapidly at $\sim 4^{\circ} \mathrm{C}$ and frozen in liquid nitrogen for later determination of plasma nonesterified fatty acids (NEFA) and TAG concentrations by enzymatic methods (glucose, TAG, Randox Laboratories, Crumlin, UK; NEFA, WAKO, Alpha Laboratories, Eastleigh, UK). In addition, a portion of the whole blood was immediately deproteinized with perchloric acid $(7 \% \mathrm{wt} /$ vol) in preparation for whole blood glycerol and glucose determination by enzymatic methods (7). All enzymatic methods were adapted to an IL Monarch centrifugal analyzer (Instrumentation Laboratory, Warrington, UK). Plasma insulin concentrations were determined with a double-antibody radiommunnoassay and were measured by using a two-site immunoradiometric assay (Pharmacia and Upjohn, Milton Keynes, UK). All samples for the hormone analysis were frozen according to the instructions of the manufacturers of the kit and then batch analyzed; the inter- and intra-assay $\mathrm{CV}$ was $<10 \%$. Some of the uncoagulated blood was also used for the measurement of hemoglobin in duplicate by using a mini-photometer (Hemocue, Boehringer Mannheim, Mannheim, Germany). Packed cell volume was also determined in duplicate after conventional microcentrifugation (Hawksley and Sons, Sussex, UK). Plasma volume changes were calculated from changes in hemoglobin and packed cell volume relative to initial resting values, as described by Dill and Costill (13).

Statistical analysis. All data are expressed as means \pm SD. Data were initially tested for normality before being analyzed by repeated-measures analysis of variance (ANOVA) with age as a between-group factor. ANOVA results were corrected by Huynh-Feldt $\epsilon$-adjusted degrees of freedom when the violation of sphericity was minimal $(>0.75)$. The Greenhouse-Geisser correction used when sphericity was violated $(<0.75)$ and when significant condition and conditiontime interactions were identified (17). Post hoc tests (Tukey's honestly significantly different) were performed to isolate any significant differences.

Student's paired $t$-tests ascertained between-condition differences when a variable was measured once. A Pearson's correlation coefficient was used to establish any relationships between variables. Statistical significance was set at $P \leq$ 0.05 for all statistical tests.

\section{RESULTS}

Exercise duration and conditions. All young subjects completed the hill walks apart from one of the subjects, who on day 9 had to rest due to fatigue and injury. Likewise, one of the older subjects had difficulties in completing some of the walks and did not manage to complete the full distances on six occasions over the 10-day study; because this subject was an outlier in most of the blood metabolic data, we decided to exclude him from the analysis of the blood parameters. The duration, distance, and ascent for the hill walks ranged between 6 and $11 \mathrm{~h}, 10$ and $35 \mathrm{~km}$, and 800 and 2,540 $\mathrm{m}$, respectively. The differences in the times to complete the walk were due mainly to variations in weather conditions and terrain. The surface conditions on the walks tended to vary with the weather. Snow and ice were regularly encountered along with high winds; these factors represent walking in very demanding climatic conditions.

Energy balance, PAL, water loss, under reporting, and under eating. Values for energy intake (EI), EEDLw, PAL, water loss, water intake, and percent under reporting during the 10 days are presented in Table 2 . The high $\mathrm{EE}_{\mathrm{DLW}}$ of $21.4 \pm 3.2$ and $21.7 \pm 2.8 \mathrm{MJ} /$ day for the two groups reflects the very high energetic cost of such hill-walking events. There was a higher incidence of under reporting of food intake in the older group when compared with the young groups $(P<$ 0.05). The reported intake was lower than the measured EE. This under reporting was approximately half due to under eating and half due to under record-

Table 2. EI, EE, BMR, PA, PA level, water intake, metabolic water values, water loss, and percentage of under recording and under eating in the different age groups

\begin{tabular}{lcc}
\hline \hline & Older & Younger \\
\hline EI, MJ/day & $15.3 \pm 1.8(12.7-17.5)$ & $19.2 \pm 3.8(13.2-24.5)^{*}$ \\
EE $_{\mathrm{DLW}}, \mathrm{MJ} /$ day & $21.4 \pm 3.2(16.8-25.7)$ & $21.7 \pm 2.8(17.8-25.4)$ \\
BMR & $7.8 \pm 0.6(7.1-8.7)$ & $7.4 \pm 0.5(6.8-7.9)$ \\
$\mathrm{PA}, \mathrm{MJ} /$ day & $18.7 \pm 5.8(11.6-26.8)$ & $19.6 \pm 3.2(14.7-23.2)$ \\
PAL & $2.8 \pm 0.9(2.3-3.3$ & $2.9 \pm 0.4(2.5-3.7)$ \\
Water intake, 1/day & $2.4 \pm 0.4(2.1-3.2)$ & $0.6 \pm 0.9(2.2-4.6)^{*}$ \\
Metabolic water, 1/day & $0.5 \pm 0.1(0.4-0.6)$ & $5.8 \pm 1.0(4.8-7.4) *$ \\
Water loss, 1/day & $4.7 \pm 0.7(3.4-5.3)$ & $-13.0 \pm 10(-30.3 \text { to }-0.7)^{*}$ \\
\hline Under-reporting, $\%$ & $-27.5 \pm 11(-46.2$ to -10.5$)$ & \\
\hline
\end{tabular}

Values are means \pm SD (range in parentheses) of 8 subjects in the older group and 9 subjects in the younger group. DLW, doubly labeled water method; $\mathrm{BMR}_{W H O}$, basal metabolic rate estimated with an equation including age, sex, body mass, and height (19); PA, triaxial accelerometer assessed physical activity; PAL, physical activity level. Refer to METHODS for calculations and assumptions. $* P<0.05$ between-group differences. 
ing. The body mass decreased on day 4 in both groups, then remained stable throughout the 10 days with a mean body mass loss of $-0.9 \pm 2.2$ and $-1.1 \pm 1.1 \mathrm{~kg}$ in the older and younger groups, respectively. The body mass loss was significant only in the younger group (day 11 vs. day $1 ; P<0.05$; Fig. 2 ). The energy equivalent of the body mass loss was $2.7 \pm 6.6$ and $3.3 \pm 3.3$ $\mathrm{MJ} /$ day [1 kg body mass was assumed to be $30 \mathrm{MJ}$ (51)] in the older and younger groups, respectively. The recorded water intake plus metabolic water was $2.9 \pm$ 0.4 and $4.0 \pm 1.0 \mathrm{l} / \mathrm{day}$. These values were significantly different from the measured water loss of $4.7 \pm 0.7$ and $5.8 \pm 1.0 \mathrm{l} /$ day in the older and younger groups, respectively $(P<0.01)$.

Daily physical activity. The daily accelerometer readings showed that the intensity of the activity was maintained throughout the 10 days. Due to the large individual variations in accelerometer output, there were no significant group or time differences in the PAL (Fig. 2).

Body composition. Changes in body composition are given in Table 3. Body fat, estimated from skinfold thicknesses, decreased by $1.3 \pm 1.2$ and $2.0 \pm 1.5 \%$ in the older and younger groups $(P<0.05)$, respectively. There were no significant differences in estimated FFM or fat mass in either group (Table 3).

Blood measurements. Results from the plasma lipid measurements are shown in Figs. 3, 4, and 5. During the morning samples, plasma TAG decreased significantly $(30-60 \%)$ during the first 5 days to reach a plateau before rising back to normal on day 11 (Fig. 3) with no significant between-group differences (statistic
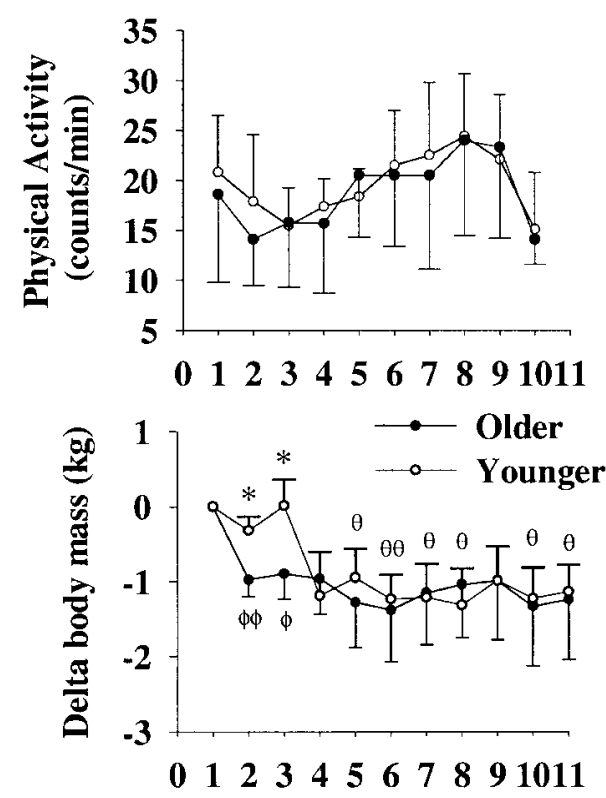

\section{Day}

Fig. 2. Physical activity levels (top) and change in body mass (bottom) throughout the experiment. Values are means \pm SD of 8 subjects in the older group ( $\bullet$ and 9 subjects in the younger group (०). * Significant difference between group differences $(P<0.05)$. ${ }^{\phi, \theta}$ Significant differences $\left(P<0.05\right.$; ${ }^{\phi \phi}$ and $\left.{ }^{\theta \theta}, P<0.01\right)$ from day 1 as a function of day in the older and younger groups, respectively.
Table 3. Change in anthropometric parameters

\begin{tabular}{lcc}
\hline \hline & Older & Younger \\
\hline Body mass, kg & $-0.9 \pm 2.2$ & $-1.1 \pm 1.1 \dagger$ \\
Fat-free mass, kg & $0.7 \pm 2.9$ & $-0.7 \pm 2.2$ \\
Fat mass, kg & $-1.9 \pm 2.5$ & $-0.3 \pm 1.5$ \\
Body fat, \% & $-1.3 \pm 1.2^{*}$ & $-2.0 \pm 1.5 \dagger$ \\
\hline
\end{tabular}

Values are means \pm SD of 8 subjects in the older group and 9 subjects in the younger group. ${ }^{*}, \uparrow$ Significant differences from day 1 as a function of day in the older and younger groups, respectively $(P<0.05)$. Refer to METHODS for calculations and assumptions.

in Fig. 3). Conversely, when measured after the walks, plasma TAG concentration declined significantly throughout the experiment in both groups (Fig. 4). In general, morning NEFA concentration remained elevated during the first 7 days before returning to normal. The older group had significantly higher circulating NEFA levels when compared with the young group (statistics in Fig. 3). Although there was a trend for higher glycerol concentrations in the morning samples compared with baseline, in both groups, this elevation did not reach significance $(P=0.093)$. Both NEFA and glycerol showed marked increases in each group when measured on completion of the walks. Blood glucose was maintained throughout the study; although there was a trend for a lower glucose level in the younger compared with older group on days 7 and 9 , this decline failed to reach significance $(P=0.096$, day $7 ; P=$ 0.052 , day 9; Fig. 4). This trend persisted when the changes in blood glucose concentrations were corrected for changes in plasma volume (13). Morning plasma insulin remained significantly lowered throughout the 10 days compared with baseline, with no betweengroup differences (statistics in Fig. 3).

Hydration and performance. The older group demonstrated a marked increase in dehydration on days 6 and 11 , relative to day $1(P<0.05$; day 11$)$, whereas the younger group remained fully hydrated throughout the 10 days (Fig. 6). Furthermore, the older group had lower perceptions of thirst compared with the younger group $(P<0.05$, day 11; Fig. 6). Table 4 gives the results for the psychomotor responses throughout the 10 days of walking. On the whole, the younger group attained higher levels in all the measured psychomotor tests when compared with the older group. Both groups showed a marked slowing of choice reaction time after the 10 days of walking. Grip strength remained unchanged on day 11 in both groups, compared with day 1. Flexibility did not change in the older group but showed a progressive increase in the younger group, whereas the vertical jump performance showed a progressive decrease in the older group, whereas it was maintained in the younger group.

The impact of the dehydration in the older group becomes apparent when the psychomotor tests are considered (Fig. 7). This change from days 1 to 11 in urine osmolality was highly corrected to the associated changes in choice reaction time and vertical-jump performance. There was a strong relationship between the increase in urine osmolality from day 1 to day 11 (i.e., 


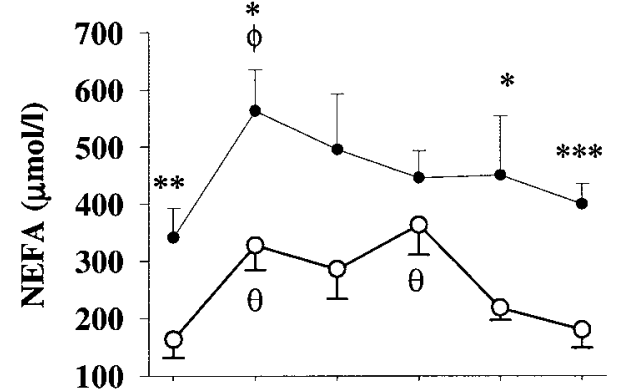

Day1 Day3 Day5 Day7 Day9Day11

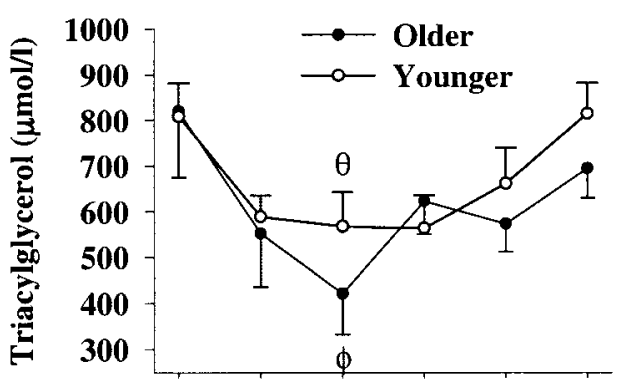

Day1 Day3 Day5 Day7 Day9Day11

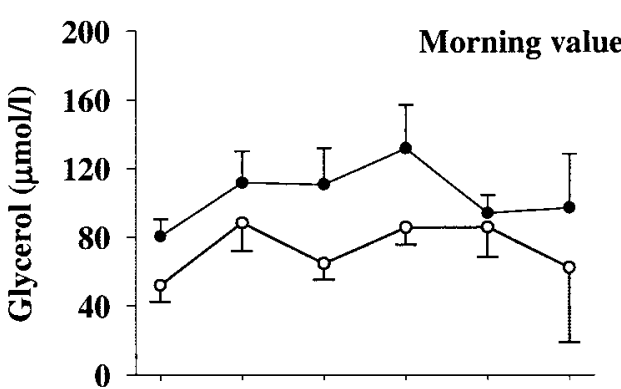

Day1 Day3 Day5 Day7 Day9Day11

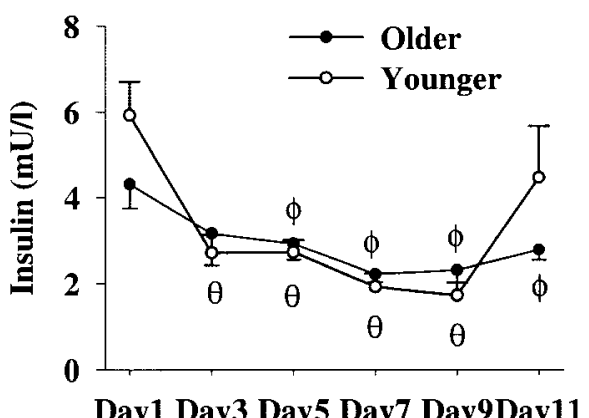

Fig. 3. Hormonal and metabolite changes during the 10-day hill walk. Values are means $\pm \mathrm{SD}$ of morning measurements of 7 subjects in the older group $(\bullet)$ and 9 subjects in the younger group (○). NEFA, nonesterified fatty acid. ${ }^{\phi, \theta}$ Significant differences $(P<0.05)$ from day 1 as a function of day in the older and younger groups, respectively. Significant between-group differences: $* P<0.05$; ** $P<0.01$; *** $P<0.001$.

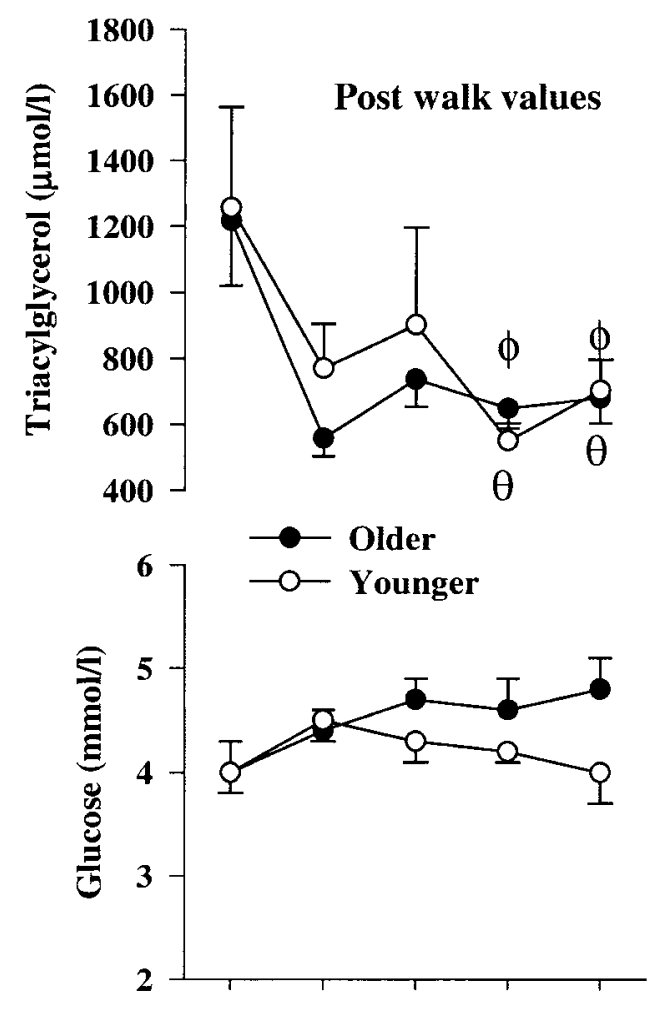

Day 1 Day 3 Day 5 Day 7 Day 9

Fig. 4. Changes in triacylglycerol (top) and glucose (bottom) immediately on completion of the walks. Values are means \pm SD of postwalk (evening) measurements of 7 subjects in the older group (•) and 9 subjects in the younger group ( ()$,{ }^{\phi, \theta}$ Significant differences $(P<0.05)$ from day 1 as a function of day in the older and younger groups, respectively. No between-group differences were present. progressive increase in dehydration) and both a slowing in choice reaction time $(r=0.79, P<0.05)$ and a decease in vertical-jump performance $(r=-0.86, P<$ 0.05; Fig. 7).

\section{DISCUSSION}

The present study has yielded a number of important findings. First, despite the very high EE and physiological stress, body mass was only marginally reduced in both groups. Second, the demanding nature of the walks was reflected in the impairment in some of the measured psychomotor tests throughout the 10 days. The impairment was more noticeable in the older subjects who also became progressively dehydrated during the 10 days. Finally, the hill walks significantly altered the hormonal and metabolic milieu in both groups. The major hormonal and metabolic perturbation in both groups was an enhanced fat mobilization, reflected in lowered plasma insulin and high plasma NEFA, glycerol and 3-hydroxybutyrate concentrations. Despite the high EE, blood glucose levels were well maintained in both groups. The maintained blood glucose levels were probably mediated via the marked fat mobilization. Enhanced fat mobilization should make it easier to maintain blood glucose by decreasing $\mathrm{CHO}$ oxidation and promoting gluconeogenesis $(2,34)$.

Energy balance. The high EE values observed in our study reflect the very high energetic cost of such hillwalking events. Despite the high EE, body mass was relatively well maintained in both groups, via high energy intakes. Comparable to the present study, Dressendorfer et al. (14) reported energy intake values of $20.2 \mathrm{MJ} /$ day in marathon runners during a 20-day $500-\mathrm{km}$ road race. Also, one of the highest energy 
Fig. 5. Metabolite changes during the 10 -day hill walk. Values are means \pm $\mathrm{SD}$ of morning (AM) and evening (PM) measurements of 7 subjects in the older group (•) and 9 subjects in the younger group (०). D, day. ${ }^{\phi, \theta}$ Significant differences $(\phi / \theta, P<0.05 ; \phi \phi / \theta \theta$, $P<0.01 ; \theta \theta \theta, P<0.001$ ) between AM vs. PM values in the older and younger groups, respectively. Significant between group differences: ${ }^{*} P<0.05$; $* *$ $P<0.01$.

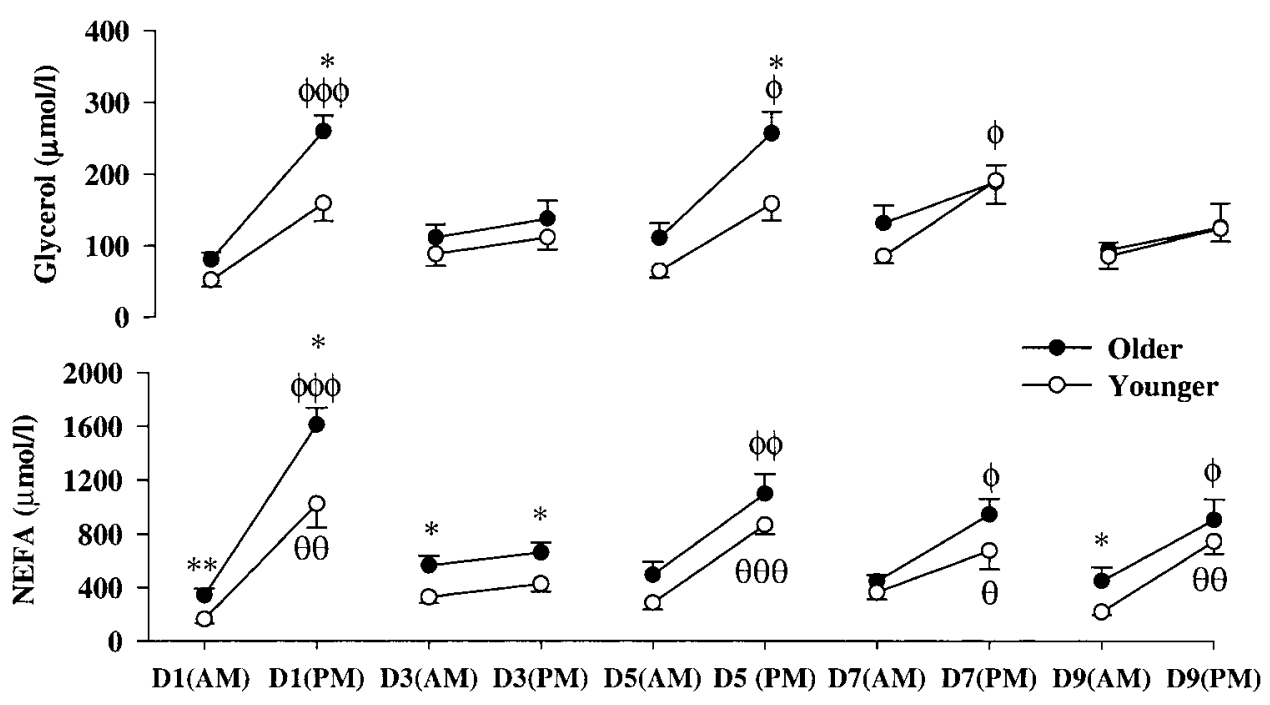

intake levels of 20-25 MJ/day reported in Maine lumbermen (54) is comparable to the present study. Indeed, only the measured EEs of $25.4 \mathrm{MJ} /$ day over 22 days in the Tour de France (53), 15.1-34.9 MJ/day in elite cross-country skiers during intensive training (43), and 25.7-32.5 MJ/day during an arctic expedition (45) reached higher values than those of the present study.

PALs or average daily multiples of BMR are commonly used to classify occupational work levels as light $(1.55 \times \mathrm{BMR})$, medium $(1.78 \times \mathrm{BMR})$, or heavy $(2.10 \times$ BMR). Work levels in this and other doubly labeled water studies on heavy work consistently exceed $2.1 \times$ BMR. The average multiple of BMR over the entire 10 days of this experiment of $\sim 2.8$ was similar to that measured over 7 and 11 days in highly trained soldiers training for jungle warfare $(2.5 \times \mathrm{BMR}$ and $2.8 \times$

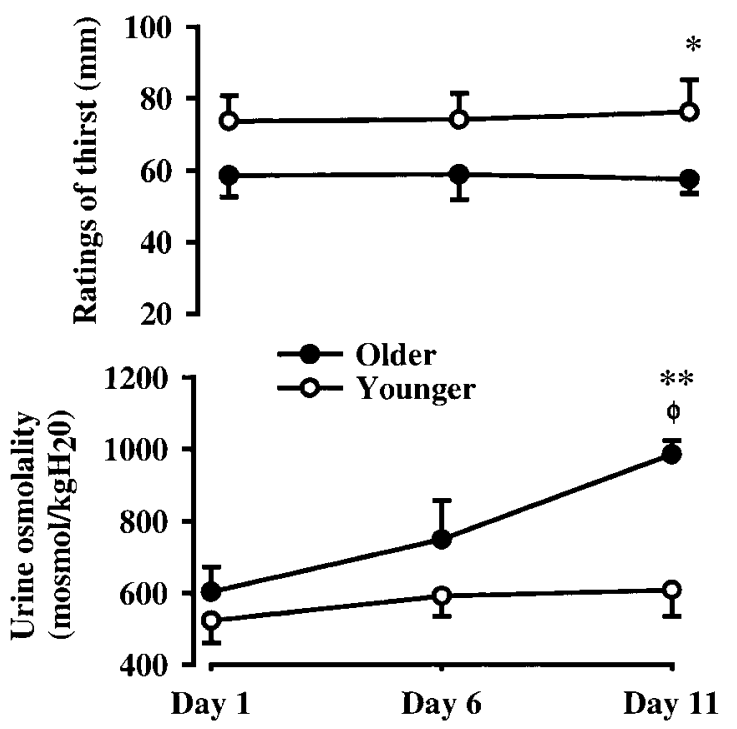

Fig. 6. Changes in urine osmolality (bottom) and ratings of thirst (top). Values are means \pm SD of 8 subjects in the older group $(\bullet)$ and 9 subjects in the younger group ( $)$. ${ }^{\phi}$ Significant differences $(P<$ $0.05)$ from day 1 as a function of day in the older group. Significant between-group differences: $* P<0.05$; ** $P<0.01$.
BMR, respectively; Refs. 20, 27), over 3.5 days in trained amateur cyclists in a study comparing room respirometry with the dry lung weight method $(2.6 \times$ sleeping metabolic rate; Ref. 50), and over 21 days in elite female athletes during rigorous training $(2.8 \times$ BMR; Ref. 33). The multiple in the present study is higher than that of humans climbing Mount Everest $(2.2 \times$ BMR; Ref. 52) but falls short of both elite cross-country skiers during high-intensity training (3.0-4.5 × BMR; Ref. 43) and the extreme rates measured over 22 days in the Tour de France (4.3 - 5.2 $\times$ BMR; Ref. 53).

In light of the high EE values and subsequent PAL data in both age groups, subjects were close to the limits of body mass maintenance (48). The important and novel consideration in the present study is that the activity was monitored during recreational activity and not with elite performers in extreme situations. Furthermore, in the present study, the effect of age did not seem to compromise the ability of the subjects to maintain energy balance. Likewise, similar changes in body composition were evident among the two groups.

Metabolism. Both groups displayed a marked increase in fat mobilization, reflected in significantly lowered prewalk insulin concentrations and elevated postwalk glycerol and NEFA concentrations. The measurements made on completion of the walks showed an enhanced lipolysis, demonstrated by up to a fourfold increase in NEFA concentrations accompanied by high glycerol concentrations. Fatty acids delivered from adipose tissue are the predominant fuel for sustained exercise at moderate intensity $(2,30)$. There is usually a surge in plasma NEFA concentrations shortly after cessation of exercise that is presumed to reflect a continued high rate of lipolysis when muscle NEFA uptake has suddenly diminished (26). This may have been partially responsible for the elevation in NEFA concentration observed in the samples postwalk. The stimulus for lipolysis during exercise is mainly adrenergic (5), reinforced by decreased insulin concentrations, as supported in the present study. However, it is 
Table 4. Psychomotor performance during the 10 days of high-intensity walking

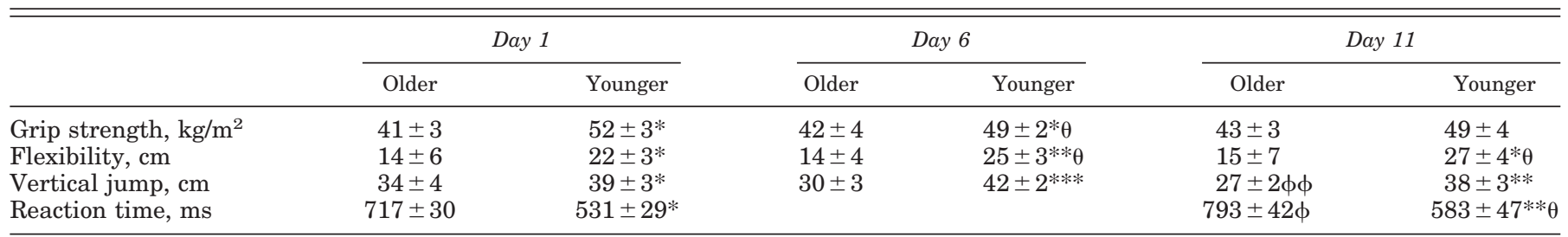

Values are means \pm SD of 7 subjects in the older group and 9 subjects in the younger group. Significant between-group differences: ${ }^{\text {a }} P<$ $0.05 ;{ }^{\mathrm{b}} P<0.01 ;{ }^{\mathrm{c}} P<0.001$. ${ }^{\mathrm{d}, \mathrm{e}}$ Significant differences $(P<0.05)$ from day 1 as a function of day in the older and younger groups, respectively.

also likely that the former stimulus was also greater in our subjects than in many exercise studies because of the adverse climatic conditions and associated physiological stress.

The decrease in TAG concentration and the enhanced fat mobilization are comparable to values reached in earlier studies after $\sim 1-3$ days of prolonged exercise and fasting $(6,16,34)$. In the studies of Carlson and Fröberg (6) and Marniemi et al. (34), subjects completed a $500-\mathrm{km}$ walk over 10 days and a $344-\mathrm{km}$ walk over 7 days, respectively. Both studies combined prolonged walking on the flat with very low-energy intakes $(\sim 837 \mathrm{~kJ} /$ day $)$. In the study of Carlson and Fröberg (6), NEFA and glycerol concentrations peaked at day 6 and then subsequently declined over the next 4 days. Similarly, TAG concentration decreased, at-

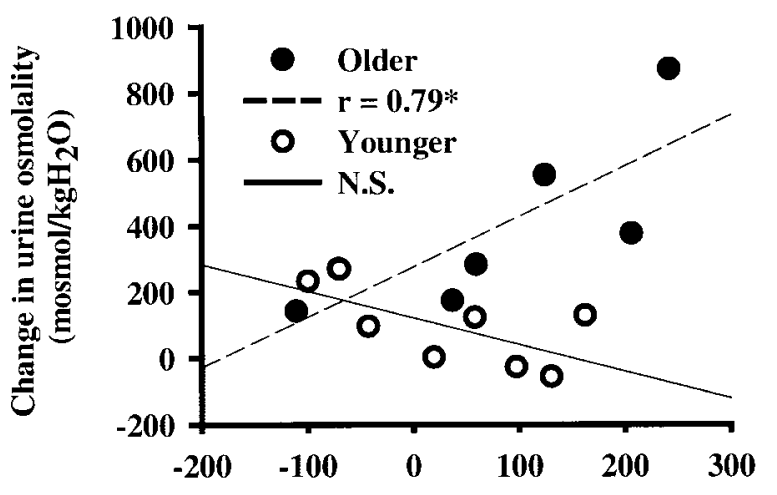

Increase in reaction time (ms)

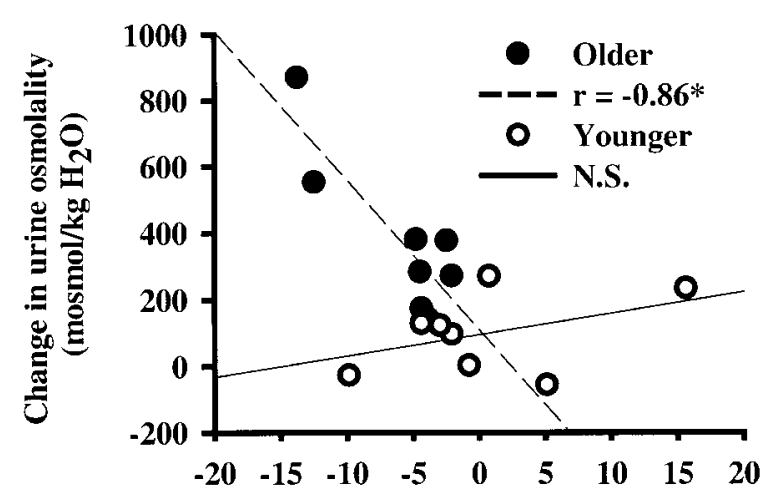

Change in jump performance $(\mathrm{cm})$

Fig. 7. Relationship between change in hydration (urine osmolality) and choice reaction time (top) or jump performance (anaerobic power; bottom $)$ * Significant relationship $(P<0.05)$. tained a plateau, and then remained stable after the first 3 days with a trend for an increase on day 7 (34). Despite the low-energy intakes in these studies $(6,34)$, both the maintained blood glucose concentration and the pattern of fat mobilization were remarkably similar to those of the present study. Because glucose was not measured during the walks, we cannot rule out the possibility of transient hypoglycemia at particular stressful times during the walks. Taking the changes in metabolism collectively, the results from the present study are comparable to those of earlier studies in which both similar prolonged exercise and low-energy intake were combined $(6,16,34)$. The results of these studies indicate that, despite low-energy intakes and high physiological stress, the human body is remarkably effective at altering its metabolism via an enhanced fat mobilization. Enhanced fat mobilization should make it easier to maintain blood glucose by decreasing $\mathrm{CHO}$ oxidation and promoting gluconeogenesis $(2,34)$. Data from the present study support the notion that older subjects are equally able to maintain their glucose concentration as their younger counterparts.

Hydration and performance. Water loss, calculated from TBW and ${ }^{2} \mathrm{H}$ turnover rates, was not covered by water input. When the effects of dehydration and TBW alterations are considered, older subjects especially were regarded to be in negative water balance. The impact of the dehydration incurred becomes apparent when the psychomotor tests are considered (Fig. 7). This change from days 1 to 11 in urine osmolality was highly correlated to the associated changes in choice reaction time and vertical jump performance. There was a significant relationship between the increase in urine osmolality from days 1 to 11 (i.e., progressive increase in dehydration) and both the slowing in choice reaction time and the decreased vertical jump performance. The reasons for the dehydration in the older subjects are unclear, but the high sweat losses, blunted thirst (especially in older subjects) (42), cold-induced diuresis, increased respiratory water losses, conscious under drinking, and poor availability of water in the field $(21,36)$ may be contributory factors. When challenged by fluid deprivation, a hyperosmotic stimulus, hypovolemia, or exercise in a warm environment, older adults exhibit a decreased thirst sensation and a reduced fluid intake (29). However, in natural environments, both the amount and pattern of fluid intake are governed by the amount and timing of food intake ( 9 , 
$10)$, and there is no apparent difference with age (11, 29). Enough fluid is consumed with meals to maintain adequate fluid balance, and under stress-free conditions the renal response is sufficient to maintain this balance (29). Although there must be a clear discrepancy in the fluid intake between the two age groups, we cannot locate whether this fluid deficiency occurred predominantly during the walks or during the periods of food intake at rest.

The finding that the older group had both higher levels of dehydration and impaired psychomotor functioning and jump performance tests is an important consideration. Both the decrease in choice reaction time and the decreased ability to employ a large muscle mass may impair decision-making abilities (e.g., leadership and navigational decisions) and potentially have an impact on injury incidence. This impaired functioning may lead to an increased incidence of injury in the mountainous environment. Furthermore, both increasing age and dehydration lead to a decrease in thermoregulatory and cardiovascular functioning $(41,42)$. Hill walkers can be caught unexpectedly and unprepared when rain and wind accompany outdoor activities in cool weather (3). Decreased thermal insulation of wet clothing presents a serious challenge to body temperature regulation, which can be compounded by fatigue associated with prolonged exercise such as hill walking $(39,40,46)$. The present results suggest that the challenge to normal body temperature regulation may be increased in older participants. Taking the observations collectively, due to the marked dehydration and impairment of psychomotor performance, older walkers may be more susceptible to fatigue and injury, and in adverse weather conditions the risk of hypothermia in mountainous environments must be considered.

In conclusion, despite high $\mathrm{EE}$, blood glucose levels were well maintained in both groups, probably mediated via an enhanced fat mobilization. Additionally, this study is the first to provide evidence that older participants, in part due to dehydration, may become compromised in their ability to operate in a mountainous environment. Further work and recommendations to both participants and rescue services are clearly warranted.

The subjects in this study deserve our special thanks. We admire their bravery to volunteer and the enthusiasm, humor, and persistence they maintained, despite the arduous testing and climatic conditions. We acknowledge the skilled technical assistance of P. Buckley, L. Dennis, R. Massey, and G. Mooney in the control and supervision of the walks.

The study was supported by Mars Inc.

\section{REFERENCES}

1. Adolph EL. Physiology of Man in the Desert. New York: Interscience, 1947.

2. Ahlborg G, Felig P, Hagenfeldt L, Hendler R, and Wahren J. Substrate turnover during prolonged exercise in man: splanchnic and leg metabolism of glucose, free fatty acids, and amino acids. J Clin Invest 53: 1080-1090, 1974.

3. Ainslie PN, Campbell IT, Frayn KN, Humphreys SM, MacLaren DPM, and Reilly T. Physiological and metabolic aspects of a hill-walk. J Appl Physiol 92: 179-187, 2002.
4. American College of Sports Medicine. Graded Exercise Testing and Exercise Prescription. Philadelphia, PA: Lea and Febiger, 1986.

5. Arner P, Kriegholm E, and Bolinder J. Adrenergic regulation of lipolysis in situ at rest and during exercise. $J$ Clin Invest 85: 893-898, 1990.

6. Carlson LA and Fröberg SO. Blood lipid and glucose levels during 10-day period of low-calorie intake and exercise in man. Metabolism 16: 624-634, 1967.

7. Coppack SW, Frayn KN, Humphreys SM, Whyte PL, and Hockaday TDR. Arteriovenous differences across human adipose and forearm tissues after overnight fast. Metabolism 39: 384-390, 1990.

8. Coyle EF. Substrate utilization during exercise in active people. Am J Clin Nutr 61: S968-S979, 1995.

9. De Castro JM. A microregulatory analysis of spontaneous fluid intake by humans: evidence that the amount of fluid ingestion and its timing is governed by feeding. Physiol Behav 43: 705$714,1988$.

10. De Castro JM. The relationship of spontaneous macronutrient and sodium intake and fluid ingestion and thirst in humans. Physiol Behav 49: 513-519, 1991.

11. De Castro JM. Age-related changes in natural spontaneous fluid ingestion and thirst in humans. J Gerontol 47: 321-330, 1992.

12. De Castro JM and Elmore DK. Subjective hunger relationships with meal patterns in the spontaneous feeding behaviour of humans: evidence for a casual relationship. Physiol Behav 43: 159-165, 1988.

13. Dill DB and Costil DL. Calculation of percentage changes in volumes of blood, plasma and red cells in dehydration. J Appl Physiol 37: 247-248, 1974.

14. Dressendorfer RH, Wade CE, Hornide C, and Timmis GC. High density lipoprotein cholesterol in marathon runners during a 20-day road race. JAMA 247: 1715-1717, 1982.

15. Durnin JW and Womersley J. Body fat assessed from total body density and its estimation from skin-fold thickness measurements on 481 men and women aged from 16 to 72 years. $B r J$ Nutr 323: 77-97, 1974.

16. Enger SC, Stømme SB, and Refsum HE. High density lipoprotein cholesterol, total cholesterol and triglycerides in serum after a single exposure to prolonged exercise. Scand J Clin Lab Invest 40: 341-345, 1980.

17. Field A. Discovering Statistics Using SPSS for Windows. Wiltshire, UK: Cromwell, 2000.

18. Fjeld CR, Brown KM, and Schoeller DA. Validation of the deuterium oxide methods for measuring average daily milk intake in infants. Am J Clin Nutr 48: 671-679, 1988.

19. Food and Agriculture Organisation/World Heath Organization/United Nations University. Energy and Protein Requirements. Report of a Joint FAO/WHO/UNU Expert Consultation. Geneva: WHO, 1985. (WHO Tech. Rep. Ser. No. 724)

20. Forbes-Ewan CH, Morrissey GC, Gregg GC, and Waters DR. Use of doubly labelled water technique in soldiers training for jungle warfare. J Appl Physiol 67: 14-18, 1989.

21. Freund BJ and Sawka MN. Influence of cold stress on human fluid balance. In: Nutrient Requirements for Working in Cold and High Altitudes, edited by Marriott BM. Washington, DC: Natl. Acad. Sci., 1995, p. 161-180.

22. Gopinathan PM, Pichan G, and Sharma VM. Role of dehydration in heat stress-induced variations in mental performance. Arch Environ Health 43: 15-17, 1988.

23. Goris AHC, Meijer EP, Kester A, and Westerterp KR. Use of triaxial accelerometer to validate reported food intakes. Am J Clin Nutr 73: 1-5, 2000.

24. Haggarty $\mathbf{P}$ and McGaw BA. Energy expenditure of elite female athletes measured by the doubly-labelled water method (Abstract). Proc Nutr Soc 47: 35A, 1988.

25. Hill AJ and Blundell JE. Sensitivity of the appetite control system in obese subjects to nutritional and serotoninergic challenges. Int J Obes 14: 219-233, 1990.

26. Hodgetts V, Coppack SW, Frayn KN, and Hockaday TD. Factors controlling fat mobilization from human subcutaneous adipose tissue during exercise. J Appl Physiol 71: 445-51, 1991. 
27. Hoyt RW, Jones TE, Stein TP, McAninch GW, Lieberman HR, Askew EW, and Cymerman A. Doubly labeled water measurements of human energy expenditure during strenuous exercise. J Appl Physiol 71: 16-22, 1991.

28. Hunter WC. Accidental hypothermia. I. Northwest Med 68: 569-573, 1968.

28a.Hunter WC. Accidental hypothermia. II. Northwest Med 68: 735-739, 1968.

28b.Hunter WC. Accidental hypothermia. III. Northwest Med 68: 837-844, 1968.

29. Kenney $\mathbf{L W}$ and Chiu P. Influence of age on thirst and fluid intake. Med Sci Sports Exerc 33: 1524-1532, 2001.

30. Kiens B, Essen-Gustavsson B, Christen NJ, and Saltin B. Skeletal muscle substrate utilization during submaximal exercise in man: effect of endurance training. $J$ Physiol 496: 459478, 1993.

31. Kreider RB. Physiological considerations in ultra-endurance performance. Int J Sport Nutr 1: 3-27, 1991.

32. Ladell WSS. The effects of water and salt intake upon the performance of men working in hot and humid environments. J Physiol 84: 410-433, 1955.

33. Levine JA, Baukol PA, and Westerterp KR. Validation of the Tracmor triaxial accelerometer system for walking. Med Sci Sports Exerc 33: 1593-1597, 2001.

34. Marniemi J, Vuori I, Kinnunen V, Rahkila P, Vainikka M, Rahkila P, Vainikka M, and Peltonen P. Metabolic changes induced by combined prolonged exercise and low-calorie intake in man. Eur J Appl Physiol 53: 121-127, 1984.

35. Noakes TD. Exercise and the cold. Ergonomics 43: 1461-1479, 2000.

36. O'Brien C, Young AJ, and Sawka MN. Hypohydration and thermoregulation in cold air. J Appl Physiol 84: 185-189, 1998.

37. Pugh LGCE. Deaths from exposure on Four Inns Walking Competition, March 14-15, 1964. Lancet 1: 1281-1286, 1964.

38. Pugh LGCE. Clothing insulation and accidental hypothermia in youth. Nature (Lond) 209: 1281-1286, 1966.

39. Pugh LGCE. Accidental hypothermia in walkers, climbers, and campers: report to the Medical Commission on Accident Prevention. Br Med J 1: 123-129, 1966.

40. Pugh LGCE. Cold stress and muscular exercise, with special reference to accidental hypothermia. Br Med J 2: 333-337, 1967.
41. Sawka MN. Physiological consequences of hypohydration: exercise performance and thermoregulation. Med Sci Sports Exerc 24: 657-670, 1992.

42. Sawka MN and Montain SJ. Fluid and electrolyte supplementation for exercise heat stress. Am J Clin Nutr 72: 564-572, 2000.

43. Sjödin AM, Anderson AB, Hogberg JM, and Westerterp KR. Energy balance in cross-country skiers: a study using doubly labeled water. Med Sci Sports Exerc 26: 720-724, 1994.

44. Strang PJH. Death due to exposure to cold in the New Zealand mountains. NZ Med J 69: 4-11, 1969.

45. Stroud MA, Coward WA, and Sawyer MB. Measurements of energy expenditure using isotope labelled water $\left(\mathrm{H}_{2}{ }^{18} \mathrm{O}\right)$ during an Arctic expedition. Eur J Appl Physiol 67: 375-379, 1993.

46. Thompson RL and Hayward JS. Wet-cold exposure and hypothermia: thermal and metabolic responses to prolonged exercise in the rain. J Appl Physiol 81: 1128-1137, 1996.

47. Westerterp KR. Body composition, water turnover and energy turnover assessment with labelled water. Proc Nutr Soc 58: 945-951, 1999.

48. Westerterp KR. Limits to sustainable human metabolic rate. $J$ Exp Biol 204: 3183-3187, 2001.

49. Westerterp KR and Bouten CV. Physical activity assessment: comparison between movement registration and doubly labeled water method. Z Ernahrungswiss 36: 263-267, 1997.

50. Westerterp KR, Brouns F, Saris WHM, and Ten Hoor F. Comparison of doubly labeled water with respirometry at low and high-activity levels. J Appl Physiol 65: 53-56, 1988.

51. Westerterp KR, Donkers JH, Fredrix EW, and Boekhoudt P. Energy intake, physical activity and body weight: a simulation model. Br J Nutr 73: 337-347, 1995.

52. Westerterp KR, Kayser B, Brouns F, Herry JP, and Saris WHM. Energy expenditure climbing Mt. Everest. J Appl Physiol 73: 1815-1819, 1992.

53. Westerterp KR, Saris WHM, Van Es M, and Ten Hoor F. Use of doubly labeled water technique in humans during sustained exercise. J Appl Physiol 61: 2162-2167, 1986.

54. Wood CD and Mansfield ER. Studies of the Food of Maine Lumbermen. Washington, DC: US Dept. Agr. Bul. no. 149, 1904.

55. Wright HF and Wilmore JH. Estimation of relative body fat and lean weight in a United States Marine Corps population. Aerospace Med 45: 301-306, 1974. 